\title{
Control of Papaya Fruits Anthracnose by Essential Oil of Ricinus communis
}

\author{
César Luis Siqueira Júnior ${ }^{*}$, Maria das Graças Machado Freire ${ }^{2}$, Antônio Sérgio \\ Nascimento Moreira ${ }^{3}$ and Maria Ligia Rodrigues Macedo ${ }^{4}$ \\ ${ }^{1}$ Laboratório Integrado de Biologia Vegetal; Universidade Federal do Estado do Rio de Janeiro; Av. Pasteur, 458; \\ 22290-240; Rio de Janeiro - RJ - Brasil. ${ }^{2}$ Laboratório de Química e Biologia; Institutos Superiores de Ensino do \\ Censa; Rua Salvador Correia, 139; 28035-310; Campos dos Goytacazes - RJ - Brasil. ${ }^{3}$ Laboratório de Ciências \\ Químicas; Universidade Estadual do Norte Fluminense; Av. Alberto Lamego, 2000; 28013-620; Campos dos \\ Goytacazes - RJ - Brasil. ${ }^{4}$ Departamento de Tecnologia de Alimentos e da Saúde; Universidade Federal de Mato \\ Grosso do Sul; Cidade Universitária; 79070-900; C. P.: 549; Campo Grande - MS - Brasil
}

\begin{abstract}
The aim of this work was to investigate the potential of castor oil for the control of papaya diseases caused by the fungus Colletotrichum gloeosporioides and the bacterium Pseudomonas caricapapayae. The treatment with 1\% castor oil did not significantly affect the fungal growth. The effectiveness of castor oil for the control of anthracnose was shown when $5 \%$ and $10 \%(\mathrm{v} / \mathrm{v})$ were used in the assays resulting in reduced mycelial growth. Fungal sporulation was strongly inhibited at $10 \%(\mathrm{v} / \mathrm{v})$ concentration of essential oil. The studies with the fresh fruits treated with $5 \%(\mathrm{v} / \mathrm{v})$ castor oil in aqueous emulsions resulted in effective reduction of pathogen spread in these fruits. No lesion was found in the fruits treated with oil, when compared to the control fruits. Castor oil showed no effect against the P. caricapapayae when tested in vitro. These results suggested the potential use of the castor bean essential oil and its fatty acids constituents for the control of anthracnose in papaya fruits.
\end{abstract}

Key words: Antimicrobial activity, essential oil, postharvest, Colletotrichum gloeosporioides, papaya

\section{INTRODUCTION}

Papaya (Carica papaya $\mathrm{L}$ ) is a perennial fruit plant belonging to the family Caricaceae and it is an important crop in Brazil and in other tropical and subtropical regions in American countries. Its culture is annually affected by a range of diseases such as anthracnose, which restricts its export to other countries. The disease is caused by the fungus $C$. gloeosporioides that has been associated with quiescent infections and postharvest diseases on other several fruits such as mango, guava, passion fruit, citrus, apple, and grapes (Alahakoon et al. 1994; Timmer et al. 1998).
Papaya plants are also attacked by the bacteria such as Pseudomonas caricapapayae that causes leaf lesions leading to the loss of nutritional values of the fruits because of sun light overexposure (Alvarez and Nishijima 1987). The control of fungi and bacteria diseases of crops is a crucial problem since the treatments, in some cases, affect the ripening process, and the use of fungicides and bactericides for extended periods may lead to the emergence of fungicide/bactericide-resistant strains of fungi and bacteria (Gamagae et al. 1993). In addition, the use of some compounds to prevent the plant infection could cause undesirable attributes either to human and animal health, or to

*Author for correspondence: cesarjunior@unirio.br 
the environment (Lo Cantore et al. 2004). Among the alternative methods that have been used for the control of various postharvest diseases are the biological control, and use of plant compounds (Lurie et al. 1995; Cowan 1999). Sodium bicarbonate associated with the yeast Candida oleophila was found to exhibit the antifungal activity against $C$. Gloeosporioides in the stored and shipped papaya fruits (Gamagae et al. 1993). Ribeiro and Bedendo (1999) demonstrated that the crude aqueous extracts from garlic, peppermint, castor bean, and pepper showed inhibitory effects on the same fungus, thus suggesting that the plant extracts have a potential use as an efficient control in relation to the physical or chemical methods. Fenner et al. (2005) analyzed the raw methanolic extracts and fractioned the aerial parts of seven plants species for their in vitro antifungal activity against a panel of standardized and clinical opportunistic pathogenic yeasts and filamentous fungi.

In recent years, the biological properties of plant extracts have been receiving attention. Many studies have pointed out the possibility to use the plant essential oils in plant pathology for the control of pathogenic microorganisms (Smith et al. 2000; Lo Cantore et al. 2004). These essential oils contain a variety of chemicals, including terpenoids which are known to be involved in the plant defense mechanism against the plant enemies (Lee et al. 2001). For this reason, these compounds have been tested against several phytopathological agents. Bowers and Locke (2004) evaluated the essential oils from mustard, neem, clove, and cinnamon for their effectiveness in reducing the populations of Phytophthora nicotianae. Wilkinson and Cavanagh (2005) demonstrated that the essential oils from several Australian plants have significant effect against the growth of some bacteria such as Escherichia coli and Staphylococcus aureus, and the yeast Candida albicans. The aim of this work was to analyze the constituents of essential oils from castor bean seeds for their ability to prevent the papaya diseases caused by Colletotrichum gloeosporioides and Pseudomonas caricapapayae.

\section{MATERIALS AND METHODS Organisms and growth conditions}

Pseudomonas caricapapayae IBSBF 2058 and Colletotrichum gloeosporioides IB 18/85 were obtained from the culture collections of the
Laboratório de Bacteriologia Vegetal of Instituto Biológico de Campinas/Brazil. They were maintained under lyophilized conditions at $4^{\circ} \mathrm{C}$. Subcultures were obtained by growing the bacteria for $48-72 \mathrm{~h}$ on SPA medium (sucrose $20 \mathrm{~g} / \mathrm{L}$, peptone $10 \mathrm{~g} / \mathrm{L}$, agar $12 \mathrm{~g} / \mathrm{L}$ ). The fungus was maintained in PDA medium (potato $4 \mathrm{~g} / \mathrm{L}$, dextrose $20 \mathrm{~g} / \mathrm{L}$, agar $15 \mathrm{~g} / \mathrm{L}$ ).

\section{Plant essential oils}

Purified castor bean essential oil ${ }^{\circledR}$ used in this study was purchased from the TALGO (São Paulo, Brazil) and its major constituents, e.g., oleic acid, linoleic acid, and ricinoleic acid were obtained from Sigma-Aldrich (Sigma-Aldrich Corp. St. Louis, Mo., U.S.A).

\section{Antifungal activity}

The fungistatic activities of the castor bean essential oil and constituents were evaluated via the poisoned food technique as described by Suberu (2004) with the following modification: a final concentration of $0.5 \% \quad(\mathrm{v} / \mathrm{v})$ Tween $-20^{\circledR}$ (Sigma-Aldrich Corp. St. Louis, Mo., U.S.A) was incorporated into the agar after autoclaving to enhance the oil solubility. Different oils concentrations $(1,5$ and $10 \%, \mathrm{v} / \mathrm{v})$ were mixed into each of three replicated plates of PDA, performing a total volume of $20 \mathrm{~mL} /$ plate, just before it solidified. PDA, with $0.5 \%$ (v/v) Tween20 but no oil, was used as a positive growth control. The plates were then centrally inoculated with single $5 \mathrm{~mm}$ diameter mycelia plug of $C$. gloeosporioides from the PDA plate and incubated at room temperature. After seven days of incubation, the mycelia growth in every plate was measured. This experiment was conducted three times, and the activity was expressed as inhibition activity (\%) of radial growth.

\section{Spore production inhibition assay}

The plates were centrally inoculated with a single $5 \mathrm{~mm}$ diameter mycelia plug of $C$. gloeosporioides. They were incubated at room temperature. After ten days of incubation, five $5 \mathrm{~mm}$ diameter mycelia plugs, from a plate of each of the concentrations, and the control were randomly harvested. The harvests per plate of every concentration were immersed in $5 \mathrm{~mL}$ distilled water in a test tube which was shaken in order to dislodge the spores. The number of spores $/ \mathrm{mL}$ from each treatment was determined using a Neubauer haemocytometer. The fungal 
sporulation with reference to the oil concentrations compared to control is presented as percentage inhibition.

\section{Effect of castor bean oil on inoculated fruits}

Papaya anthracnose caused by $C$. gloeosporioides was used as a model system for in vivo studies. Papaya fruits at color stage 4 (more yellow than green) were purchased in the local market. Eight papaya fruits were surface sterilized with $75 \%$ ethanol, and each fruit was wounded $(0.5 \mathrm{~cm}$ deep and $0.2 \mathrm{~cm}$ diameter) in three positions on the surface. Wounded fruits were inoculated with a 0.1 $\mathrm{cm}$ disc of conidia suspension of $C$. gloeosporioides and held at $28^{\circ} \mathrm{C}$ for $2 \mathrm{~h}$. Four of the inoculated fruits were then dipped either in $1 \mathrm{~L}$ of $5 \%(\mathrm{v} / \mathrm{v})$ castor bean oil containing $0.2 \%$ Tween-20 for $15 \mathrm{~min}$. The control treatment consisted of dipping a set of four inoculated fruits in water with $0.2 \%$ Tween-20 for $15 \mathrm{~min}$. The fruits were allowed to air dry for $5 \mathrm{~min}$ after the treatments and were maintained for 7 days at $28^{\circ} \mathrm{C}$. At completion of the incubation period, the lesion diameter was measured in centimeters $(\mathrm{cm})$.

\section{Antibacterial activity}

Antibacterial activity of castor bean oil was determined using the disc diffusion assay as described by Wilkinson and Cavanagh (2005). The $P$. caricapapayae was cultured for $24 \mathrm{~h}$ and prepared fresh for each assay. SPA plates $(15 \mathrm{~mL})$ containing $0.5 \%$ tween- 20 were prepared, allowed to set, and the surface dried at $37^{\circ} \mathrm{C}$ for $30 \mathrm{~min}$. One milliliter of the bacterial culture was subsequently poured evenly over the surface of the dried agar plates, and the plates were incubated at $37^{\circ} \mathrm{C}$ for approximately $20 \mathrm{~min}$, until the bacterial overlay dried. One hundred microliter of each oil concentration, $100 \%$ (v/v, undiluted), $50 \%(\mathrm{v} / \mathrm{v})$ and $10 \%(\mathrm{v} / \mathrm{v})$ in nutrient medium were pipetted onto $10 \mathrm{~mm}$ sterile filter paper discs. The discs were then placed on the agar plate and the plate was incubated at $28^{\circ} \mathrm{C}$ for $48 \mathrm{~h}$. The diameters of the inhibition zones for each dilution were recorded in millimeters $(\mathrm{mm})$, including the discs. In the control discs, $100 \mu \mathrm{L}$ nutrient medium were pipetted.

\section{Statistical analysis}

Data are presented as the mean \pm S.D. of three independent experiments, and the differences from the control were assessed with the Student's t-test; statistically significant at $P<0.05$.

\section{RESULTS AND DISCUSSION}

Of the million plant species on Earth, only a small percentage has been investigated for its antimicrobial activity. Ricinus communis seeds are known to be poisonous to humans and other mammals due to the presence of toxic proteins which have toxic properties. However, its essential oils have been used for a long time in the human medicine because of their purgative properties (Upasani et al. 2003). In this study, the castor bean essential oil and its constituents were examined for their antimicrobial activity against the anthracnose agent in the papaya fruits, C. gloeosporioides. Significant differences were observed in the fungal growth, when the fungi were added to the PDA micro plates containing the castor bean oil. The growth inhibition was effective with as low as $1 \%$ concentrations of the oil when compared to fungal growth in the control plates (in absence of oil) (Fig. 1A). Higher concentrations of the oil imposed higher inhibitions and modifications on the mycelial growth (Fig. 1 B-C). Studies have already shown the growth inhibition activity on different organisms by a large number of essential oils from plants, including the macadamia, carrot (Harmer et al. 1999), miller (Wilkinson and Cavanagh 2005), and mustard (Bowers and Locke 2004). The spore production inhibition is presented in Figure 2. Percentage inhibition on the sporulation of $C$. gloeosporioides by the castor bean essential oil ranged from 65 to $70 \%$ in comparison to the control. Suberu (2004) has reported the sporulation inhibition of Aspergillus flavus by the extracts of two lichens.

To reinforce this idea, papaya fruits, inoculated with $C$. gloeosporioides, were dipped in 5\% castor bean oil solution, and maintained at $28^{\circ} \mathrm{C}$ for 7 days to evaluate the inhibitory effects from the castor bean essential oils in vivo. The naturally infected fruits subjected to the treatment revealed significantly lower anthracnose incidence and severity than the control fruits (Fig. 3). 

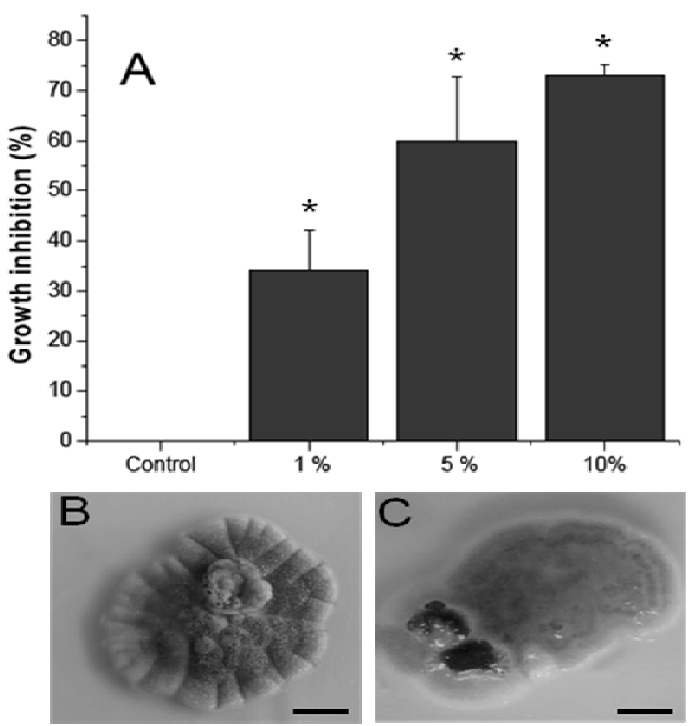

Figure 1 - A) Percentage inhibition of mycelial growth of C. gloeosporioides in concentrations of the castor oil. The values represent the means \pm S.D. in triplicates obtained from three independent experiments. Asterisks denote significant difference t $P<0.05$ (Student's $t$-test) from control. B) C. gloeosporioides grown in the absence of castor oil. C) $C$. gloeosporioides grown in the presence of castor oil (10\%). Photographs were taken after a 7-day incubation period.

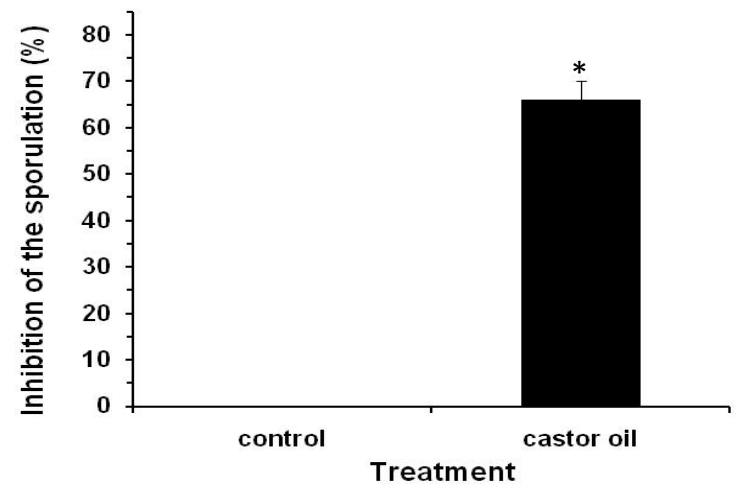

Figure 2 - Percentage inhibition of spore production in C. gloeosporioides by castor oil at $10 \%$ concentration. Data are means of triplicates obtained from three independent experiments ( \pm S.D.). Asterisk denotes significant difference t $P<0.05$ (Student's $t$ test) from control.

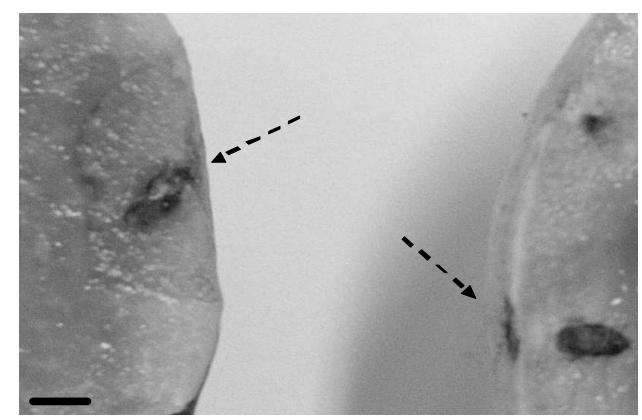

Figure 3 - Effect of castor oil on anthracnose incidence in naturally infected papaya fruits. Black bar means $3 \mathrm{~cm}$ on the photograph. The result is a representative picture of one among three independent experiments. Inoculation sites (arrows). 
It is clear from the results that the application of castor bean essential oil on papaya had inhibitory effects against $C$. gloeosporioides in both the inoculated and naturally infected fruits during the storage. The castor oil did not show significant antimicrobial activity against $P$. caricapapayae (data not shown). Castor oil has been previously described by the absence of bactericidal activity against $P$. syringae, $P$. putida (Upasani et al. 2003). This result was very interesting, because essential oils from several plant sources have been described as a potent natural bactericide for the control of various bacterial diseases of plants (Lo Cantore et al. 2004; Iacobellis et al. 2005). Studies suggest that plant pathogens have differential sensitivity to plant compounds (Padmavati et al. 1997). The resistance of the Pseudomonas species to castor oils could be due to a co-evolutionary adaptation to the essential oils constituents. The antimicrobial activity of individual major fatty acids components of castor oils (Table 1) was further analyzed.

These observations showed that the major inhibitory activity in castor oil was due to ricinoleic acid (Fig. 4). On the other hand, an interesting feature was observed when $C$. gloeosporioides was treated with oleic acid. At $10 \%$ concentration, there was a slight growth inhibition.

Table 1 - Components of the essential oil of castor bean (Ricinus cummunis).

\begin{tabular}{cc}
\hline Fatty Acid & Range of average composition $(\%)$ \\
\hline Ricinoleic Acid & $85-95$ \\
Oleic Acid & $2-6$ \\
Linoleic Acid & $1-5$ \\
Linolenic Acid & $0.5-1$ \\
Stearic Acid & $0.5-1$ \\
Palmitic Acid & $0.5-1$ \\
Dihydroxystearic Acid & $0.3-0.5$ \\
Other & $0.2-0.5$ \\
\hline
\end{tabular}

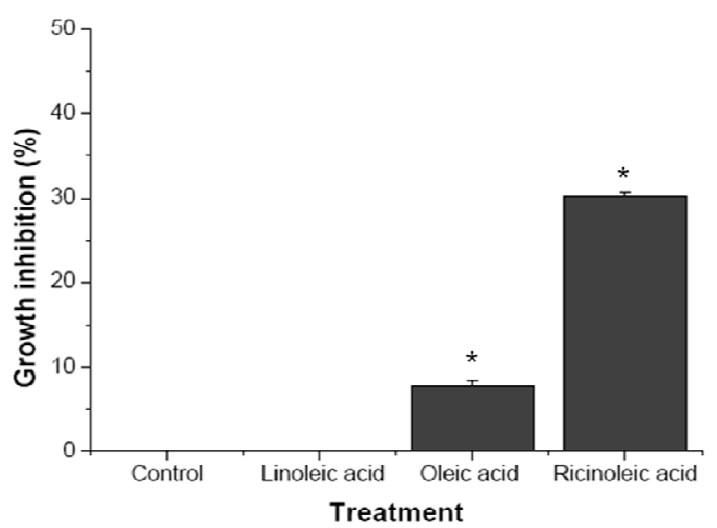

Figure 4 - Inhibition of $C$. gloeosporioides growth in PDA medium by supplementation with exogenous fatty acids. The values represent the means \pm S.D. in triplicates obtained from three independent experiments. Asterisks denote significant difference t $P<$ 0.05 (Student's $t$-test) from control.

The results suggested that the activity of the castor oil could be due to the mixture of fatty acids. Fatty acids, as well as their corresponding salts, have been reported to display the antimicrobial activity (Nieman 1995; Sprong et al. 2001; Skrivanova et al. 2005). Despite the lack of elements which would make the inhibitory mechanism fully understood, it has been assumed that the fatty acids penetrate the lipid membrane and dissociate in the more alkaline interior causing the metabolic uncoupling (Russell and Diaz-Gonzalez 1998). In addition, the high inhibition caused by the ricinoleic acid could be due to its cytolytic activity by being a solvent of chitin, constituent of the cell membrane of fungi, while the oleic acid has potential antifungal properties attributed to long- 
chain unsaturation (Agoramoorthy et al. 2007). Thus, these findings could be significant for an understanding of the basis of the $R$. communis oil effect on C. gloeosporioides.

\section{ACKNOWLEDGEMENTS}

The authors are grateful to Dr. Maria Ligia R. Macedo for her support. This research was supported by the Institutos Superiores de Ensino do CENSA - (Campos dos Goytacazes - RJ Brazil).

\section{REFERENCES}

Agoramoorthy G, Chandrasekaran M, Venkatesalu V, Hsu J. Antibacterial and antifungal activities of fatty acid methyl esters of the blind-your-eye mangrove from India. Brazil J Microbiol. 2007; 38: 739-742.

Alahakoon PW, Brown AE, Sreenivasaprasad S. Crossinfection potential of genetic groups of Colletotrichum gloeosporioides on tropical fruits. Mol Plant Pathol.1994; 44: 93-103.

Alvarez AM, Nishijima WT. Postharvest diseases of papaya. Plant Dis. 1987; 71: 681-686.

Bowers JH, Locke JC. Effect of formulated plant extracts and oils in population density of Phytophthora nicotianae in soil and control of Phytophthora blight in the greenhouse. Plant Dis. 2004; 88: 11-16.

Cowan MM. Plant products as antimicrobial agents. Clin Microbiol Rev.1999; 12: 564-582.

Fenner R, Sortino M, Kuze Rates SM, Dall'Agnol R, Ferraz A, Bernardi AP, et al. Antifungal activity of some Brazilian Hypericum species. Phytomedicine. 2005; 12: 236-240.

Gamagae SU, Sivakumar D, Wilson Wijeratman RS, Wijesundera RLC. Use of sodium bicarbonate and Candida oleophida to control anthracnose in papaya during storage. Crop Protect. 1993; 22: 775-779.

Iacobellis NS, Lo Cantore P, Capasso F, Senatore F. Antibacterial activity of Cuminum cyminum L. and Carum carvi L. essential oils. J Agric Food Chem. 2005; 53: 57-61.

Lee SE, Lee BH, Choi WS, Park BS, Kim JG, Campbell BC. Fumigant toxicity of volatile natural products from Korean spices and medicinal plants towards the rice weevil, Sitophilus oryzae (L.). Pest Man Sci. 2001; 57: 548-553.
Lo Cantore P, Iacobellis NS, De Marco A, Capasso F, Senatore F. Antibacterial activity of Coriandrum sativum L. and Foeniculum vulgare Miller Var. vulgare (Miller) essential oils. J Agric Food Chem. 2004; 52: 7862-7866.

Lurie S, Drobey S, Chalupowicz L, Chalutz E. Efficacy of Candida oleophila strain 182 in preventing Penicilum expansum infection of nectarine fruits. Phytoparasitica. 1995; 23: 231-234.

Nieman C. Influence of trace amounts of fatty acids on the growth of microorganisms. Bacteriol Rev. 1995; 18: 147-163.

Padmavati M, Sakthivel N, Thara KV, Reddy AR. Differential sensitivity of rice pathogens to growth inhibition by flavonoids. Phytochemistry. 1997; 46: 499.

Ribeiro LF, Bedendo IP. Efeito inibitório de extratos vegetais sobre Colletotrichum gloeosporioides agente causal da podridão de frutos de mamoeiro. Sci Agric. 1999; 56: 1267-1271.

Russell JB, Diaz-Gonzalez F. The effects of fermentation acids on bacterial growth. $A d v$. Microbiol. Physiol. 1998; 39: 205-234.

Skrivanova E, Marounek M, Dlouha G, Kanka J. Susceptibility of Clostridium perfringens to $\mathrm{C} 2-\mathrm{C} 18$ fatty acids. Lett Appl Microbiol. 2005; 41: 77-81.

Smith MAL, Marley KA, Seigler D, Singletary KW, Meline B. Bioactive Properties of Wild Blueberry Fruits. J Food Sci. 2000; 65: 352-356.

Sprong RC, Hulstein MFE, Van der Meer R. Bactericidal activities of milk lipids. Antimicrob Agents Chemother. 2001; 45: 1298-1301.

Suberu H. Preliminary studies of inhibitions in Aspergillus flavus with extracts of two lichens and bentex-T fungicide. Afr J Biotechnol. 2004; 3: 468472.

Timmer LW, Brown GE, Zitko SE. The role of Colletotrichum gloeosporioides spp. in postharvest anthracnose of citrus and survival of $C$. acutatum on fruit. Plant Dis. 1998; 82: 415-418.

Upasani SM, Kotkar HM, Mendki PS, Maheshwari VL. Partial characterization and insecticidal properties of Ricinus communis L foliage flavonoids. Pest Man Sci. 2003; 59: 1349-1354.

Wilkinson JM, Cavanagh HMA. Antibacterial activity of essential oils from Australian native plants. Phytother Res. 2005; 19, 643-646.

Received: November 08, 2010; Revised: January 20, 2011; Accepted: November 07, 2011. 